The earliest date on which the comet appears to have been seen in South Africa was January 12, when, at I4h. $25 \mathrm{~m}$. (G.M.T.), some workmen at the Transvaal Premier Diamond Mine saw it. They described it as an ordinary star with a tail to it, apparently a little to the tight of the point where the sun rises. Apparently $\mathrm{Mr}$. Innes was nearly as unfortunate as some London astronomers, for, having made a series of observations on the morning of January 17 , he and his colleagues were pre$v \in$ nted, by overcast skies, from seeing the comet again.

A number of observations now recorded in the same journal and in the Comptes rendus show that the comet's brightness decreased very rapidly after January 30 , and this probably accounts for the disappointment of a large number of people in not seeing it after reading the accounts of its extraordinary brilliancy and beauty. M. Coggia found that on February $I 1$ it was but a bright nebulosity about equally visible with a star of magnitude 8.4 ; on February 4 it was as faint as magnitude $7 \cdot 6$, and only sinowed faint traces of a tail near the nucleus.

Halley's Comet.-An interesting popular address delivered before the Jersey Society in London by Mr. W. B. Brodrick in December (rgog) is now published in Science Progress (No. 15, p. 492). The address contains a discussion of the historical events which have coincided with the comet's known apparitions, especially that of 1066, and some interesting quotations from early writers are given.

It is now improbable that the comet will be seen again until the third week in April, when, until its transit on May 18, it will rise shortly before the sun almost due east.

The Sun-spots of Septamber 25, 1909.-An interesting description of the sun-spots of September 25 , illustrated by photographs taken with the Rumford spectroheliograph at the Yerkes Observatory, is given by Dr. Slocum in No. I, vol. xxxi., of the Astrophvsical Journal (January, p. 26). The history of the spot, shown to be connected with the magnetic storm of September 25, is given from its appearance on September I to November I9, when it was last seen, and the Yerkes observations confirm those made at South Kensington in showing that the spot was especially active at the time of the magnetic storm. On September 24 the high-level calcium flocculi showed a spiral form over the spot but on September 25 this had disappeared, and was replaced by a number of bridges crossing the spot. On September 27 the arrangement of these bridges had changed completely, and there was again a trace of the spiral structure. A prominence plate taken on September 30 , at 3 h. $48 \mathrm{~m}$. G.M.T., showed that the spot area was still active for there were several prominences at the region of the limb where the spot had disappeared; a second plate, taken at 4 h. $57 \mathrm{~m}$. G.M.T., showed that in the interval a violent eruption had occurred, and in place of a small sincle prominence there was a brilliant one extending some $5^{\circ}$ or $6^{\circ}$ along the limb, and rising, in several arches, to a height of $32,000 \mathrm{~km}$.

Displacementr of Lines at the Sun's Limb.-In publishing his important results on the spectroscopic determination of the sun's period of rotation, Dr. Halm, in 1907 , directed attention to several cases where there were small displacements, of certain lines, independent of those due to rotation. Since then the matter has been under investigation at Mount Wilson, and Mr. W. S. Adams now publishes, and discusses at length, the results obtained. Too many points of interest are raised in his paper to be discussed adequately here, but one or two of the chief ones may be briefly referred to.

A great deal of the work has been carried out with the 3o-foot spectrograph, used in connection with the towe telescope, thus providing photographs of large dispersion.

Seven classes of lines were selected for special discussion, so that anv differential effects might be the better investigated. and altogether 470 lines were dealt with; the intensities at limb and centre, the displacement, and various remarks are tabulated for each line. Two values for the displacement are given, one the observed value, the other the value obtained after applying to this a correction of $0.002 \AA$. indicated by the cyanogen bands as being probably due to motion in the line of sight produced by convection currents in the values for the centre.

These results show that the lines of titanium, vanadium, and scandium are less displaced than those of iron and nickel, and this is considered to be an indication that the cause producing the relative "shifts" is most effective at the lower levels. Lines most strengthened at the limb generally show the smaller displacements, and the explanation offered is that the intensification is a temperature effect, the higher level lines being cooler; the smaller displacement is thus in accordance with the previous conclusion.

The enhanced lines are well marked in the results, and generally show a much greater displacement than the arc lines. This is especially prominent in the case of lines extremely weak in, or absent from, the arc spectrum, as shown by the special study of eighteen lines given in Lockyer's list of the enhanced lines of iron; the line at $\lambda 4385.548$ gives a larger displacement (+o.013 A.) than any other line on the more refrangible side of $\lambda \quad 5500$. The suggested explanation of this peculiarity of enhanced lines is that, in the solar suectrum, they are due almost exclusively to the "granulations" on the disc. If, as has been suggested, these granulations signify masses of ascending, heated vapours, the measures at the centre would be affected by the resulting differential motion in the line of sight, and so increased displacements would result; an upward motion of $0.12 \mathrm{~km}$. per sec. in the granulations would account for the results found.

Finally, the results indicate that the relative displacements are caused by pressure, although this is a general result to which there are exceptions, which further investigations may adequately explain. The action of magnetic fields, of anomalous dispersion, and various other causes are referred to, but more evidence is necessary ere their definite relation can be inferred.

The "Anuario" Of the Madrid Observatory, igio.From the Madrid Observatory we have received a copy of their "Anuario" for 19ro, a useful volume containing the usual astronomical tables and some interesting articles on astronomical subjects. There is also a résumé of the solar observations made at the observatory during 1908. containing a complete daily, and summarised, record of the prominence observations, and a similar résumé of the meteorological observations.

\section{THE ORGANISATION OF INDUSTRIAL} RESEARCH.

$A \mathrm{~N}$ address delivered by $\mathrm{Mr}$. W. $\mathrm{R}$. Whitney at the twentieth anniversary of Clark University, and reprinted from the Journal of the American Chemical Society in two recent numbers of the Chemical Ner's, contains many suggestive and valuable passages, expressed with characteristic forcefulness. As the author is himself at the head of a staff of eighty investigators, he is well qualified to speak on the "Organisation of Industrial Research." In his view the fundamental problem is to secure men who are endowed with the essential qualities of optimistic activity and knowledge; the former he regards as of supreme importance, in view of the fact that general laws usually indicate the impossibility of a process rather than the specific conditions under which success may be achieved. Fortunately this quality can be imparted, as has been proved again and again, by the establishment of "schools" of research, many of which have become world-wide in their operation; fortunately, also, it is possible by suitable organisation to utilise the labours of those who are not so endowed to promote the achievement of the ideals conceived by the few who are; and in such an organisation it is urged that the output should be not merely proportional to the number employed, but to some higher exponential function. In such a complex scheme it is not thought to be possible to reward each investigator by royalty or by any such direct payment for his success in making discoveries of definite commercial value, on one hand because his success is only in part due to his own efforts, and on the other hand because each investigator must be freely available for carrying on lines of work in which success of this kind is not likely to ensue. 
In regard to material equipment, the author holds views of a very advanced character. Necessity is not the mother of invention; knowledge and experiment are its parents. This is clearly seen in the case of many industrial discoveries; high-speed cutting tools were not a necessity which preceded, but an application which followed, the discovery of the properties of tungsten-chromium-iron alloys; so, too, the use of titanium in arc lamps and of vanadium in steel were sequels to the industrial preparation of these metals, and not discoveries made by sheer force of necessity. Much the same consideration applies to the equipment of an industrial laboratory, where the most useful tools were often acquired with no idea of the uses to which they would ultimately be put. "No good tool lives long for a single use alone. Many times we have questioned the advisability of installing some new apparatus-a vacuum furnace, a pair of metal rolls, some special galvanometer, some microscope, a hydraulic press, a power hammer, a steam digester, \&c. Never, after it became a part of the equipment, has it seemed possible to proceed without it. In the single case of the electric vacuum furnace, for example, our laboratory has made almost continual use of from three to eight for the past five years. The laboratory, piped several years ago with high vacuum and with electrolytic hydrogen, besides steam, air, water, and gas, will probably never operate without them.",

Similar considerations apply to a library. A library containing ten of the leading research journals of the world may be said to have in each volume about 100,000 brainpower hours, and it would be folly not to utilise a charged storage-battery of this immense capacity when it can so readily be installed.

\section{SOME RECENT APPLICATIONS OF OZONE.}

A LTHOUGH ozone has now been definitely known for nearly seventy years, its commercial production and resulted from the modern development of electrical engineering. The "Ozonair" Company, of 96 Victoria Street, Westminster, has taken advantage of these developments to produce a series of compact and (in many cases) portable ozonisers which can be connected directly to the ordinary lighting circuits and set in operation by means of a couple of tumbler switches, one controlling a fan or blower, and the other a coil or transformer for energising the aluminium gauze in contact with which the ozone is produced. The simplicity of these arrangements should prove an important factor in securing the general utilisation of ozone in all those cases in which its usefulness has been conclusively demonstrated.

Most of the new designs are intended for the purification of air, and in the case of large buildings their utility and efficiency can scarcely be doubted. In a small room or in close proximity to a generator, the presence of an excess of ozone might well be disagreeable, as those who have worked with it have good reason to know, but in a crowded hall the atmosphene of a public meeting would stand to gain enormously by the freshening and purifying effects of one or two well-placed ozonisers. In cases such as the above it is difficult, and in many buildings impossible, during the winter to introduce enough air from outside to prevent the atmosphere from becoming "stuffy," but the most dangerous and unpleasant effects might well be got rid of by means of ozone.

This general idea has been worked out into a definite and novel scheme of ventilation, which is acquiring considerable popularity in Russia, where warmth and freshness have usually presented themselves as alternatives rather than as compatible qualities, and in the tropics, where the introduction of large volumes of air from the outside is sufficient to destroy whatever remnants of coolness may be retained by the use of verandahs and other devices for excluding the glare of the sun. In each of these widely differing circumstances the method used is to withdraw air from the room, purify it by screening, washing, and ozonising, cool or warm as the case may be, and return it to the room with a sufficient admixture of outside air to keep the proportion of carbon dioxide within reasonable limits. In this way a great economy of NO. 2 Io6, VOL. 83] heating or cooling is achieved, whilst the wholesomeness of the atmosphere is fully maintained.

The sterilisation of air by means of ozone has found a widespread application in brewing, where it replaces with great advantage the cumbrous and only partially effective systems of air-filtration that have been employed to protect the wort during fermentation, cooling, refrigerating, and bottling; it is also of service in protecting the yeast from contamination whilst it is being drained off from the wort.

An application of ozone of a more familiar type is in the bleaching of palm-oil for soap-making. This has usually been effected by means of bichromate and muriatic acid at a cost which may amount to as much as 30 s. per ton. The bleaching of the oil by ozone is very effective, even in the case of specially bad samples, and costs little more than a tenth of this sum; in addition, the dark sediment that is thrown out during purification is much smaller in bulk, and the waste of oil is therefore greatly reduced.

It is claimed that the ozonised air produced by the new types of apparatus is entirely free from oxides of nitrogen, a point of considerable importance in many of its commercial applications.

\section{AMERICAN ECONOMIC ENTOMOLOGY.}

A CCORDING to the twenty-fifth report of the State Entomologist on the noxious and beneficial insects of Illinois, the scope of the work of the Entomological Department of that State has been very largely increased as the result of special legislative enactments, and the present report is the first to be drawn up under the new conditions. Its contents consist of three articles, one on experiments to check the corn-root aphis, a second on the habits of the corn-field ant (Lasius niger americanus), and a third on the insects infesting clover and alfalfa. Since all three have been already issued as Bulletins of the Agricultural Experiment Station of Illinois University, they need not be further noticed.

The mites of the group Oribatoidea form the subject of an article in vol. vii. of the Bulletin of the Illinois State Laboratory of Natural History. These mites, which are not much larger than the head of an average pin, are characterised by their hard, chitinous integument, on account of which they are commonly spoken of as beetle-mites, although they are not to be confounded with the mites infesting coprophagous beetles. They are generally found under decaying timber, beneath bark, under stones, in moss or grass, or on the twigs of trees, and do not appear to inflict any special damage on crops. In the present article Mr. H. E. Ewing describes a number of new species.

In article 2 of vol. viii. of the same publication $\mathrm{Mr}$. J. D. Hood gives descriptions of new generic and specific types of thrips of the group Thysanoptera from Illinois.

Army-worms and cut-worms infesting sugar-cane in the Hawaiian Islands form the subject of Bulletin No. 7 of the Entomological Division of the Experiment Station of the Hawaiian Sugar-planters' Association, published at Honolulu. Of the various species of "army-worms," the widely spread Cirphis unipuncta is abundant in the islands, but the larvæ do not seem to assemble in the hordes which have given rise to the name of the group. They inflict, however, considerable damage on young sugar-cane, although, fortunately, there is an interval between the disappearance of one brood and the development of a second, which affords time for the plants to recuperate. The numbers of the grass army-worm-the caterpillars of the moth Spodoptera mauritia, a species indigenous to Mauritius, western Africa, and the Oriental and Australasian regions-have been kept in check in Hawaii, where they formerly did much damage, by the introduction of myna birds from India.

Since weevils are a group with which the economic entomologist has many dealings, reference may be made here to a paper on North American Curculionidæ, by $\mathrm{Mr}$. W. D. Price, published as No. 1708 of the Proceedings of the U.S. National Museum. A number of new species are named and described. 